\title{
Safety Scheme for Mining Industry using Zigbee Module
}

\author{
N. Krithika* and R. Seethalakshmi \\ School of Computing, SASTRA University, Thanjavur, Tamil Nadu-613401, India; \\ nkrithika33@gmail.com, rseetha123@cse.sastra.edu
}

\begin{abstract}
This work proposes a safety scheme for coal mining industry using sensors and zigbee. The zigbee built safety scheme with precise remote monitoring and tracking is the most suitable life saving system for underground mining environment. The LPC2148 based underground sensor module continuously monitors and transmits data to the tracking module using zigbee. The PIC protective device wore by labor helps to identify their location using zigbee and the associated limit switch alerts labor in case of improper wearing of PPE. The voice unit attached to underground sensor module gives an emergency command based on the analysis of monitored parameters. In addition the tracking module helps to locate workers through the signal relayed by zigbee protective device. Thus the safety system for coal mining regions with ability to track and alert via voice command forms a complete protective system for underground labors.
\end{abstract}

Keywords: ARM LPC2148, PIC, Personal Protective Equipment (PPE), Sensors, Zigbee

\section{Introduction}

Inside the mines, communication is essential to protect the workers from any eventualities. To enhance both production and safety in mines, an authentic communication is established between a fixed base station and workers involved in the underground mining. But, inside the mines, wired communication is very difficult to reinstall in case of landslide or any damage. Owing to the special environment of the underground mining system, there is no perfect way to resolve the data transmission problems. Recently WSN technology evolved and provides better solution for data acquisition with a secured monitoring system in the mining industry. In coal mine supervising system, the important aspect is to observe temperature, humidity and toxicant gas released and to chase underground miners to rescue of coal mine catastrophe and safety production. A cost efficient Zigbee is supported by wireless mine monitoring system with early warning tidings on temperature, $\mathrm{CH}_{4}$ (methane) and humidity in the mining area. It can be applied to mine safety production and management.

Mining accidents are caused by leakage of poisonous gas, explosive natural gases especially $\mathrm{CH}_{4}$, collapsing of mine stopes, flooding, dust explosions and seismicity. In 2013, almost 80 members have died due to above mentioned problems. It can be resolved by the embedded controller which collect the sensor's level of nearby environment and alert the transmitter and receiver side, in case of abnormal condition through Zigbee. Industrial workers have to pursue several working principles. If they are not pursuing, obligation dwells with the company. In industrial area, the most important rules for workers is to use Personal Protective Equipment (PPE) such as helmets, gloves, boots, harness, goggles, etc. It performs to forbid the natural calamity from unmanageable risk. The main aspect of PPE is to provide a guarantee to the worker safety. 


\section{Survey}

Various toxic gases such as $\mathrm{CH}_{4}, \mathrm{H}_{2} \mathrm{~S}$ and $\mathrm{CO}$ present inside the drainage and the detection of these gases can be done by embedding electronic sensor in labors' helmet. If any toxic gas found by three different sensors such as MQ4, MQ7 and $\mathrm{H}_{2} \mathrm{~S}$ nano sensor, then labors get intimated by alarm and also oxygen supply would be given to solve the asphyxiation problem of labors ${ }^{1}$. In fire detection system $\mathrm{CH}_{4}$ detection technique is generally applied and also infrared absorption scheme was used to achieve safe, stability and long working span. This scheme gets derived from Lambert-Beer law to constitute infrared absorption $^{2}$. There are various monitoring technique are used to monitor the hazardous area. In mining area, the hazardous and vulnerable component of air can be monitored by real time through nRF2401. It is then coupled by msp430 through serial peripheral interface for information transfer and elaborating peripheral device to improve flexibility and practical ability ${ }^{3}$. In underground mines the density of gas can be monitored through LAN or WLAN in order to trigger the alarm in monitoring unit in case of any emergency condition ${ }^{4}$. WSN based mine gas monitoring system was successfully constructed by using system software. This system software was prepared by Tiny OS nesC structure programming language. By measuring gas density for an aforementioned time, the real time environmental information can be send to the user through SMS by using GPRS technology ${ }^{5}$. The defense in depth rule was established to lead the protection levers, technology, regulatory and logistic/supervisory to upgrade the protection in mining industry. The aim is to cut down the casualty rate and to improve the recent protection circumstances. It can be comforted by mining manipulator and governors ${ }^{6}$. Network coordinator of monitoring gateway can act as full function device which is a link between the wired and wireless network. CAN bus is utilized to transfer the information between the monitoring unit and underground unit, which decrypts the data from CAN bus and employs sound to find the infinite spot consorting to address label'. TinyOs supported by WSN of green house surveillance system is monitored by using msp430 and nesC language. For control application Visual basic which is easy to learn, convenient, simple efficient and better interface design capability makes the remote constraint between monitoring system and $\mathrm{PC}^{8}$. The system collects all information from remote constraint unit and it is controlled by visual basic GUI ${ }^{9}$.

\section{Project Description}

Analysis of the system can be made in three fragments specifically underground unit, worker PPE and monitoring unit as shown in Figure 1.

\subsection{Underground Unit}

In underground mine, environment could not be stable in order to offer safety to protect the workers from dangerous effects. Protections has to be rendered for both humans and mine as coal endeavor is a risky occupation and leading cause for mine disaster are toxic gases. Important factors to be monitored in order to defend the mines endlessly are toxic gases like $\mathrm{CO}$ and $\mathrm{CH}_{4}$, position of coal at bunker, pressure and temperature. Every formulated individual coal mines has to be communicating with observing block sporadically to ensure safety. So, In Underground unit system electronic sensors are embedded diversely in different sectors to gather an assortment of environmental parameters which embraces temperature, humidity and $\mathrm{CH}_{4}$ gas. This can be done by ARM7 (LPC2148) and values are sending to the monitoring unit. Voice Command is used to alert the underground mine worker, when abnormal condition cropped up in mine using Voice IC (APR9600). When temperature level exceeds the Saturation level, command gets produced in the underground unit as "Emergency temperature abnormal". Similarly when gas and humidity sensor level exceeds then corresponding command gets produced. In existing system when sensor level is exceeding the threshold level instantly the alarm get triggered, but the disadvantage is worker doesn't know which sensor is exceeding the normal level. To avoid these situations, the system proposes a new technique as voice command is used to alert the worker and the worker can send out immediately depends upon the sensors. The system accomplished multiple advantages for observ-

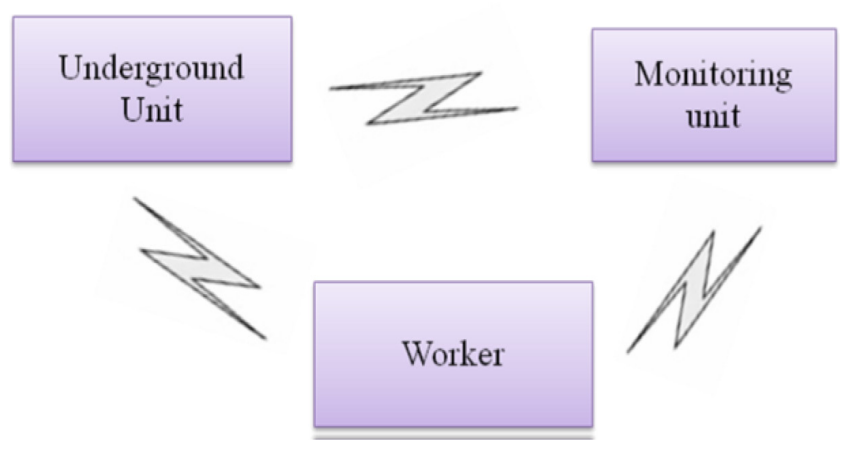

Figure 1. Block diagram of proposed system. 
ing, controlling mine production and safety management along with low power incineration platform.

\subsection{Worker PPE}

For the purpose of safety precaution, the PIC controller based device will be provided to every worker, which detects the bearing of PPE. If PPE was not wear out by worker then alert the worker by means of alarm. Zigbee observe the locomotion of workers in mine with aid of Visual Basic software.

\subsection{Monitoring Unit}

To monitor the various segment of underground mine and also report the status in which place the worker are presented in mines like Room 1, Room 2 and so on. Zigbee Transceiver is used to transmit the sensor's data and the number of personnel inside the coalmine could be supervised from ground station. By doing, so miners can be shielded protectively to reduce fatalities The proposed system of three unit are shown in Figure 2.

\section{Hardware Description}

\subsection{Types of Sensors}

Sensor is used to measure the physical quantity and converts it into signal which can be read by an instrument or observer (See Tables 1-3).
Table1. Features of temperature and humidity sensor

\begin{tabular}{|c|c|c|}
\hline & Temperature sensor & Humidity sensor \\
\hline Principle & $\begin{array}{l}\text { The temperature } \\
\text { sensor senses the } \\
\text { environmental } \\
\text { condition } \\
\text { and produces } \\
\text { corresponding voltage } \\
\text { proportional to room } \\
\text { temperature at the } \\
\text { range of } 10 \mathrm{mv} /{ }^{\circ} \mathrm{C} \text {. }\end{array}$ & $\begin{array}{l}\text { By using humidity } \\
\text { sensor humidity } \\
\text { content of gas can } \\
\text { be measured and } \\
\text { relative humidity can } \\
\text { be calculated from } \\
\text { ratio between vapor } \\
\text { pressure in air and to } \\
\text { specified temperature. }\end{array}$ \\
\hline $\begin{array}{l}\text { Operating } \\
\text { voltage }\end{array}$ & $4 \mathrm{~V}$ to $30 \mathrm{~V} \mathrm{DC}$ & $5 \mathrm{~V} \mathrm{DC}$ \\
\hline Power & Less than $60-\mu \mathrm{A}$ & $<3.0 \mathrm{~mA}$ \\
\hline Accuracy & $\begin{array}{l}0.5^{\circ} \mathrm{C} \text { Ensured } \\
\text { Accuracy }\end{array}$ & $+/-5 \% \mathrm{RH}$ \\
\hline Range & $-55^{\circ} \mathrm{C}$ to $+150^{\circ} \mathrm{C}$ & 10 to $90 \% \mathrm{RH}$ \\
\hline $\begin{array}{l}\text { Output } \\
\text { Voltage }\end{array}$ & $\begin{array}{c}\text { For every } 1^{\circ} \mathrm{C} \\
\text { increases in output } \\
\text { voltage of } 10 \mathrm{mV}\end{array}$ & 990 to $2970 \mathrm{mV}$ \\
\hline Stability & Excellent & Good \\
\hline Condition & $\begin{array}{l}\text { Normal - 270mv } \\
\text { Extreme - 380mv }\end{array}$ & $\begin{array}{l}\text { Normal - } 60 \\
\text { Extreme - } 80\end{array}$ \\
\hline Problem & $\begin{array}{l}\text { Temperature exceed - } \\
\text { Explosion occur }\end{array}$ & $\begin{array}{l}\text { Humidity abnormal - } \\
\text { Difficulty to breathe }\end{array}$ \\
\hline Application & $\begin{array}{c}\text { Industrial and } \\
\text { Remote Applications }\end{array}$ & $\begin{array}{c}\text { Industrial and } \\
\text { weather monitoring } \\
\text { Applications }\end{array}$ \\
\hline
\end{tabular}

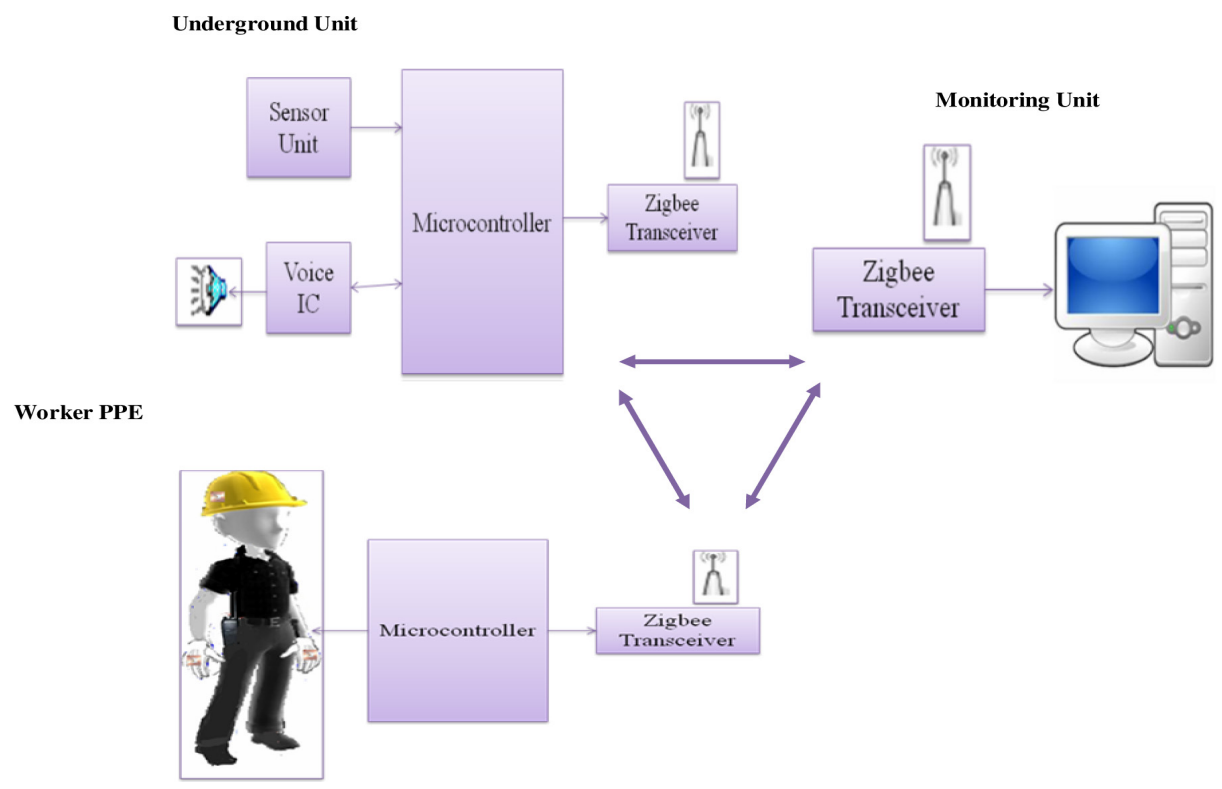

Figure 2. Block diagram of underground unit, worker PPE and monitoring Unit. 
Table 2. Features of gas sensor

\begin{tabular}{|c|c|}
\hline \multicolumn{2}{|r|}{ Gas Sensor } \\
\hline Operating voltage & less than 24volt DC \\
\hline Principle & $\begin{array}{l}\text { The gas sensor functions by } \\
\text { determining the vicinity of gas } \\
\text { by discharging corresponding } \\
\text { amount of current in that device. }\end{array}$ \\
\hline Temperature & $20^{\circ} \mathrm{C}$ \\
\hline Humidity & $65 \%$ \\
\hline $\mathrm{O}_{2}$ concentration & $21 \%$ \\
\hline Concentration of $\mathrm{CH}_{4}$ & 200-10000ppm \\
\hline Smell of $\mathrm{CH}_{4}$ & Odorless \\
\hline Atmospheric lifetime & 12 to 15 years \\
\hline Relative Density(Air=1) & 0.6 \\
\hline Problem & $\begin{array}{c}\text { Methane gas is increase - } \\
\text { Asphyxiation problem occur. }\end{array}$ \\
\hline Application & $\begin{array}{c}\text { Waste Water Treatment, Battery } \\
\text { Rooms, Mechanical/chiller } \\
\text { Rooms, Mining }\end{array}$ \\
\hline
\end{tabular}

Table 3. Features of voice IC

\begin{tabular}{ll}
\hline & APR9600 \\
\hline Process & $\begin{array}{l}\text { Single Chip, High Quality } \\
\text { Audio/Voice Recording \& } \\
\text { Playback Solution }\end{array}$ \\
Operating Voltage & $3 \mathrm{~V} \sim 6.5 \mathrm{~V}$ \\
Playback capability & 40 to 60 seconds \\
Very Law Standby Current & $-1 \mathrm{uA}$ \\
Low Power Down Current & $15 \mathrm{uA}$ \\
Resolution & Up to $16-$ Bits \\
Sampling rate & $4-8 \mathrm{KHz}$ \\
Advantages & No requirement of Battery \\
& Backup, User Friendly \\
\hline
\end{tabular}

\subsection{PPE}

For the specified application, the PPE should control the risk factors to attain complete shelter. To avoid the risky situations and disaster, various equipment such as gloves, helmets, goggles, boots and harness are utilized to furnish the safety guarantee to the workers.

\section{Result and Discussion}

This proficiency is mainly used to monitor and control the underground mine and also provide safety system to avoid the health hazards. Three different sensors are used to continuously monitor the underground mine environment consisting gases like $\mathrm{CH}_{4}$, temperature and humidity. They are controlled and connected by low power ARM processor LPC2148. Zigbee acts as a transceiver. Zigbee transmitter is used to transmit the sensors information to monitoring unit. When sensors exceed the saturation level, IC APR9600 is used to generate the command to alert the worker in underground unit. It makes the worker to know which sensor level get exceeds. Another advantage of proposed system includes the monitoring section which helps to know the situation of underground mines, so as to avert the workers who are working at the hazardous region until the place return back to the normal level.

Every worker should wear the PPE for their self safety. How worker check their own PPE is worn correct or not? PIC controller is connected to the PPE to check whether it is worn perfectly and also it alerts the worker with alarm in case of not worn the equipment properly. Zigbee forms the mesh topology, When worker enter in to the underground mine room 1, the workers should carry the device with zigbee, which helps to communicate with underground mine zigbee device and transmit the information to ground unit through zigbee. The monitoring section includes visual basic software in order to track the presence of workers. So this technique is used to find the person where they are present inside the mine.

The hardware snapshot of underground unit as shown in the Figure 3.

Hardware Snapshot of worker worn the PPE properly as shown in Figure 4 and worker worn the PPE improper as shown in Figure 5.

Hardware snapshot of monitoring unit as shown in Figure 6. VB software is used to to display the sensor

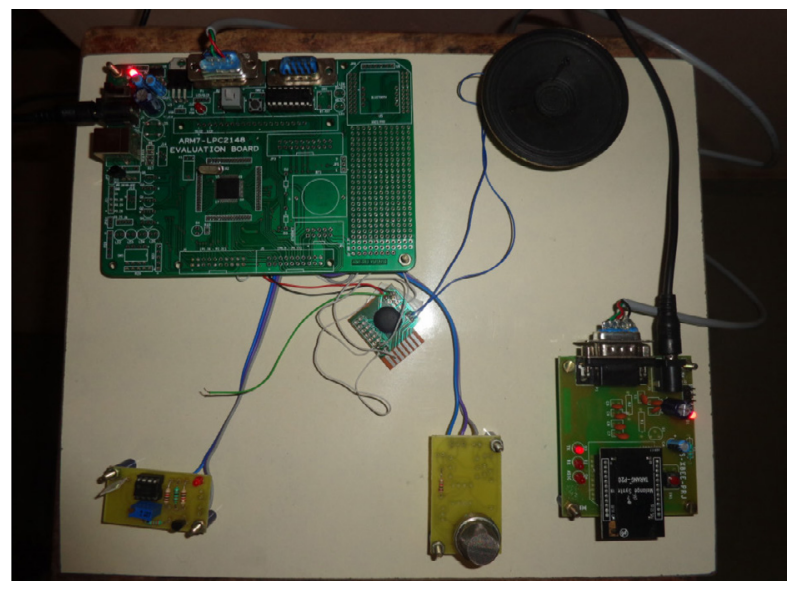

Figure 3. Hardware snapshot of underground unit. 


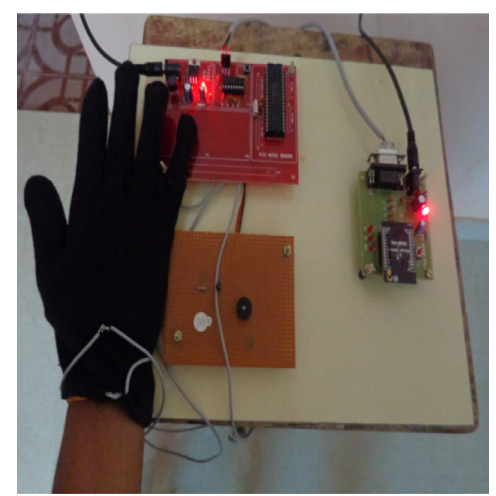

Figure 4. Worker worn PPE properly.

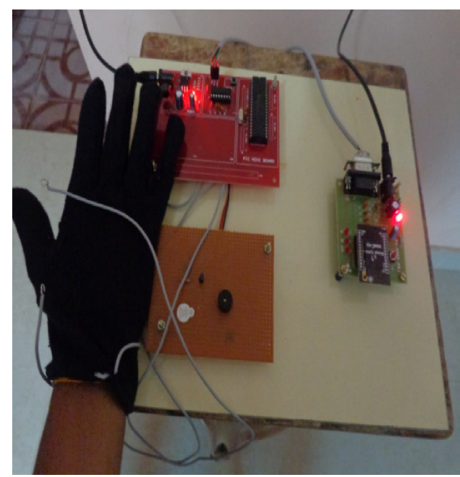

Figure 5. Worker Worn PPE improper.

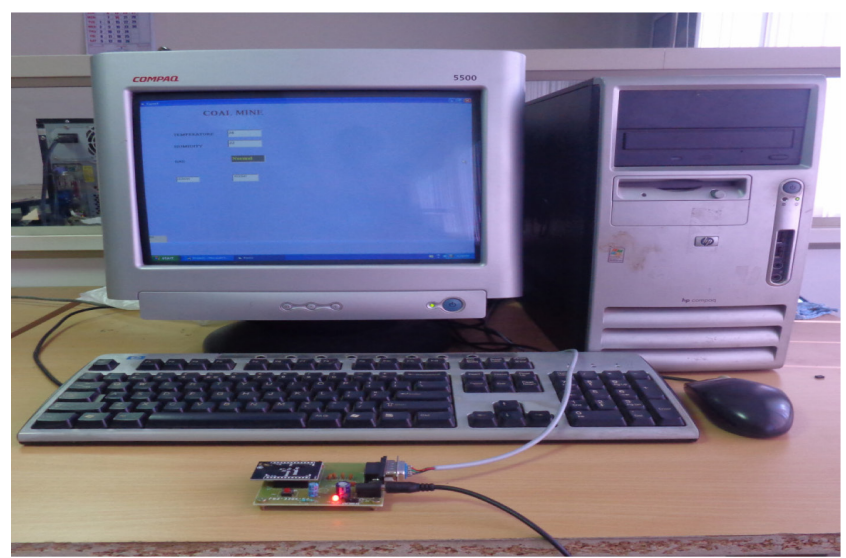

Figure 6. Hardware snapshot of monitoring unit.

value and worker presence. Sensors value at normal condition as shown in Figure 7 and sensors value at abnormal condition as shown in Figure 8.

\section{Conclusion}

The work proposal is to identify hazards at various locations in a certain work module. Nowadays world's most

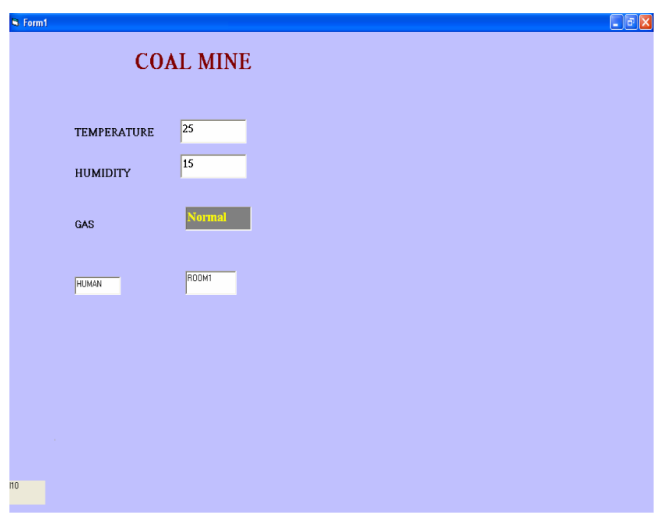

Figure 7. VB Display of sensor value at normal.

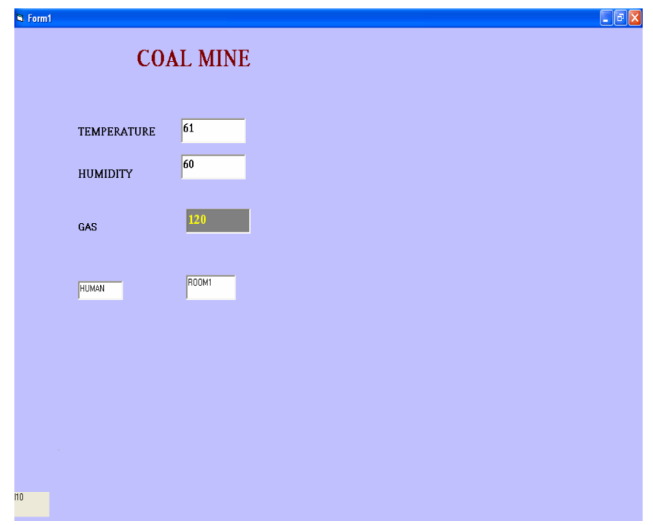

Figure 8. VB Display of sensor value at normal condition.

hazardous industries, advanced gas detection technique has been used in saving many lives. In the field of remote monitoring and sensing innovative applications can be developed by WSN technology. In order to reduce the coal mine accidents, WSN technology has followed and the sensors of gas $\mathrm{CH}_{4}$, temperature, humidity can be used. Mine safety monitoring system use zigbee module to monitor the underground parameters of a coal mine, worker's present location and avert the mine from catastrophes. The system can monitor not only the environmental parameter of underground mine, voice command also can be automatically generated, when environment parameters are abnormal which helps to meliorate the monitoring level for safety production and subdue the coal mine accidents. The zigbee will help to find the miner's location, which are present inside the underground coal mine. By implementing this method rescue mission has been automated thereby saving time and life of the rescuers and workers. As every individual worker is provided with their own information regarding hazardous environment they could minimize any 
communication gap at the time of rescue or reaching out for safety.

\section{Acknowledgement}

The authors are thankful to SASTRA University, School of Computing, Embedded system lab for providing the technical support while the project was being carried out.

\section{References}

1. Krithika N, Dineshkumar K, Hemalatha M. An embedded toxic gas alert system. Int J Appl Eng Res. 2014; 9(4):409-17

2. Wen-Qing W, Lei Z, Wei-hua Z. Analysis of optical fiber methane gas detection system. Procedia Engineering. 2013; 52:401-07.

3. Song J, Zhu Y, Dong F. Automatic monitoring system for coal mine safety based on wireless sensor network. Cross Strait Quad-Regional Radio Science and Wireless Technology Conference; 2011.
4. Rong L. A study of the security monitoring system in coal mine underground based on WSN. 2011; IEEE

5. Gao LL. Design of mine gas monitoring system based on wireless sensor network. 2013; 756-59, 603-06.

6. Saleh JH, Cummings AM. Safety in the mining industry and the unfinished legacy of mining accidents: Safety levers and defense-in-depth for addressing mining hazards. Safety Science. 2011; 49:764-77.

7. Xianli Q, Mingchao F, Bin S. Coal mine gas wireless monitoring system based on WSNs. Second International Conference on Digital Manufacturing \& Automation. 2011; IEEE.

8. Gao R, Zhou H, Su G. A wireless sensor network environment monitoring system based on TinyOS. 2011 International Conference on Electronics and Optoelectronics (ICEOE 2011); 2011.

9. Dange KM, Patil RT. Design of monitoring system for coal mine safety based on MSP430. International Journal of Engineering Science Invention. 2013 Jul; 2(7):14-19. 